\title{
Business Research In Eight Business Disciplines
}

Larry M. Robinson (E-mail: lrobin@ rice.edu), Rice University Roy D. Adler (E-mail: roy.adler@pepperdine.edu), Pepperdine University

\begin{abstract}
This study recorded nearly 1.5 million citations to measure research productivity of the 4,918 full time faculty members with doctoral degrees at 51 leading US business schools. These schools had been included at least once in the 25 most recent ranking lists produced by three major business publications. This research included lifetime citation counts for each faculty member, and resulted in 1,497,162 citations that were recorded between March and June 2003.

The citation counts were cumulated by academic discipline. The disciplines for which rankings were made were accounting, economics, finance, information systems, marketing management science, organizational behavior, and strategy. Ranked lists of the top 25 schools in each disciple are included.

The paper contains a review of the literature on citation analysis, and suggests how citation analysis might be used as an assessment tool by business school administrators, professors, students, and corporate managers.
\end{abstract}

\section{Introduction}

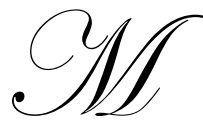

easuring the quality of academic faculties is a task that is both easy and difficult. It can be extremely easy, because one has only to ask the apparent leaders in the academic discipline, record their assessments of the reputations of various faculties, and draw conclusions based on their opinions. This can be done in a single day.

A more rigorous approach is to examine quantitative factors that might go into the recipe for reputation. Chief among them is the number of publications. The implicit assumption is that an author with a great number of publications has his or her work read very frequently by others in the field, and that the more often a $\mathrm{n}$ author is read, the more impact he or she has on the thinking of others.

The difficulty with this line of reasoning is that it is based on quantity of production, because only the number of articles is tallied. There is no attempt to measure whether the articles have influence or, in fact, whether they are even read by anyone. It could be, for example, that an author might have published dozens of articles, but none of the articles were ever used by anyone else to shape their thinking. In that case, an author rated fairly high in production quantity would be rated very low on measures of impact on others.

Impact measures would be very valuable, but they are elusive. It would not seem to be an easy task to determine the impact of the 4,918 full time faculty members with doctoral degrees at 51 leading US business schools. That task was accomplished using citation analysis, however, and the results are presented here as a series of rankings of the productivity of each school's business research in eight academic disciplines. 


\section{Background On Citation Analysis}

Citation analysis is a process that measures the number of times a published article has been referenced in other articles worthy of publication. The overall concept is to regard an article as having impact if a subsequent author deems it important enough to merit citing it in her own published work. Authors, articles, and journals with the most citations can logically be considered to have had the most impact. The process can be used to measure that impact of individual articles, the impact of the authors of those articles, the impact of institutions, or the impact of groups of articles. In this particular case, it measures the impact of one school's faculty in a given discipline.

Citation analysis became an accepted method for analysis of research quality in the natural sciences in the early 1960s following the introduction of the Science Citation Index (SCI). In 1969, the Social Science Citation Index (SSCI) became a new source of information about the citation practices of major journals in the social sciences. Since that time the number of social science journals included in SSCI has grown to about 1,700, with many of the journals including all citations dating back to 1975 .

A citation is recorded when an article in one of the 1,700 journals indexed by SSCI has referenced a previous work, and that previous work is credited with the citation. Citation analysis is an established procedure for the analysis of contributions to knowledge, dissemination of knowledge, and extent of knowledge exchange in a given field (Garfield 1979), and is a way of tracing the development of thought in a discipline. Citation analysis can be used for several purposes, including evaluation of scientists, publications and institutions, investigation of hypotheses concerning the history or sociology of science and technology; and in the study of information search and retrieval procedures. (Peritz 1992).

Citation analysis has several advantages over other methods of evaluating research productivity in that it is objective, quantifiable, and a logical measure of quality. It is evidence that an article has not only been published, but has been read and referenced by someone else in an article good enough to be published in a journal included in the SSCI. The reference provides evidence of influence on the author who referenced it. As a quantifiable indication of influence on the work of others, it is an objective measure of research quality. Citation analysis has also been correlated with scientific productivity and peer judgments of performance (Bayer and Folger 1966).

Citation analysis is not without issues, and citation practices vary greatly by author. A critical review of citations analysis by MacRoberts and MacRoberts (1989) examined the issues in use of citation counts, including biased citing, self-citing, and difficulties in treating citations of multiple authors for an article. The article also noted variations in citation rate related to type of publication, nationality, time period, and size of specialty area. Low citation rates for many journal articles suggest much of published work in social science journals does not get read (Mahoney 1987, Hamilton 1991).

The first known use of citations in the marketing discipline was the measurement of the impact of marketing scholars and institutions over the four-year period 1972-1975 (Robinson and Adler 1981). The accounting discipline began to use citation analysis to assess the impact of journals and articles in accounting research (Brown and Gardner 1985). In 1990, the Journal of Financial Economics provided citation index rankings, and Alexander and Mabry (1994) ranked journals based on the number of citations, and identified the 50 most cited journals and the 50 most-cited authors in finance for the time period 1987-1991. Borokhovich, Bricker, and Simkins (1994) studied 15,110 footnotes appearing in 685 articles in eight major finance journals for 1990-1991, and concluded that two journals provided the research core of finance research, most journals publish in a greater variety of areas than they have influence, and there was a low level of borrowing across disciplines.

The applied operations research journal Interfaces used citations analysis to examine 1,294 articles, 2,194 authors, and over 2,500 citations over a 23 year period (Gupta 1997). Gupta found that about 48 percent of articles were never cited, and the average number of citations for those with at least one citation was 3.63. He also found that most citations occurred in the first three years after publication. Vincent and Ross (2000) provide perhaps the strongest recent review of the literature on citations analysis, and its uses and potential uses in business research. Both advantages and pitfalls are highlighted in their work. 


\section{Method}

This study was designed to extend previous work done by authors who identified and ranked business schools based on measures of research productivity. Earlier work in this area was limited in scope, due primarily to a limited ability to access relevant data. For instance, most studies of business school research productivity focused on a specific discipline, or on a specific journal for a limited time period.

The design of the present study benefits from recent advances in information technology. The researchers were able to gather all data needed for the study by using unobtrusive means. The study was divided into three phases.

The first phase began by identifying the set of US business schools ranked in the top 30 at least one time by well-known business school ranking systems (Business Week, US News and World Report, and Financial Times) over the period 1988 to 2003 . The next step was to identify the faculty members to be included in the study, and to record the following data for each.

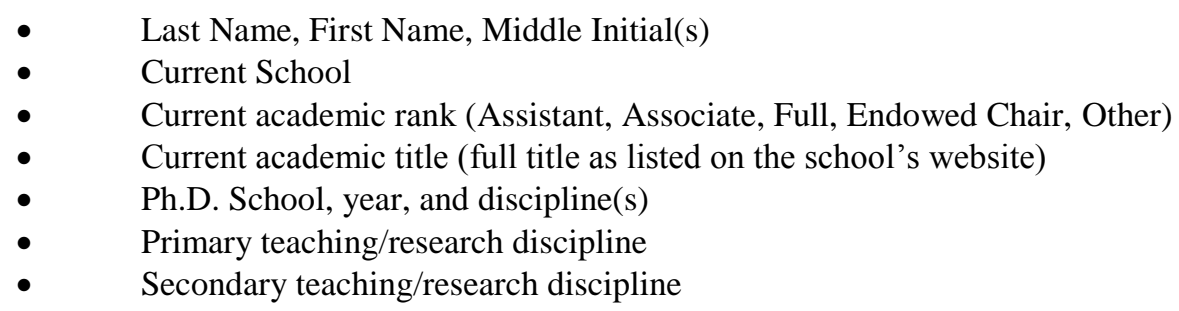

School websites varied greatly in the amount of information available. For those instances when supplemental information was needed, the researchers used Digital Dissertations, internet search engines, and directories for faculty (Hasselback, 2002).

The second phase of the study gathered citations data for each of the 4.918 faculty members identified in the first phase. The researchers used the Web of Knowledge to gather lifetime citations data from online data compiled and updated weekly by the Institute for Scientific Knowledge (ISI) from the SSCI. The endnote provides details about the process used to develop lifetime citation counts. All citation counts were captured between March 1 and June 30, 2003.

The third phase ranked the 51 business schools in various ways using the citation count data. Total and average citation counts were developed for the faculty members of the 51 schools, so rankings could be generated for the 51 schools and for eight academic disciplines within the 51 schools. The resulting rankings based on citation counts were compared with rankings for the disciplines developed US News and World Report for perceived research quality.

\section{Results}

The results were based on 1,497,162 citations, which was a snapshot of the lifetime citation counts for the 4,918 full time faculty members at the 51 business schools included in the study. The faculty members at these schools were then sorted into eight academic disciplines of interest, which were: accounting, economics, finance, information systems, marketing, management science, organizational behavior, and strategy. Ranked lists of the top 25 schools in each disciple were then developed.

Table 1 is an alphabetical list of the 51 business schools included in the study. The 51 schools are all the schools that have been listed as being in the top 30 at least once by Business Week, US News and World Report, and Financial Times. There were 25 rankings lists generated by these publications between 1988 and 2003. 
The eight columns show the rank order for each university in a given discipline. The order is based on the mean number of citations for the business faculty within the discipline under examination. The mean number was chosen as the primary indicator, in order to more accurately reflect the research productivity of each faculty member.

The table shows that a surprisingly large number of schools dominate the lists. Four schools were ranked within the top 30 for all eight disciplines (i.e. Chicago, Harvard, MIT, and Stanford) but nine schools were within the top 30 seven times, and nine additional schools were ranked six times.

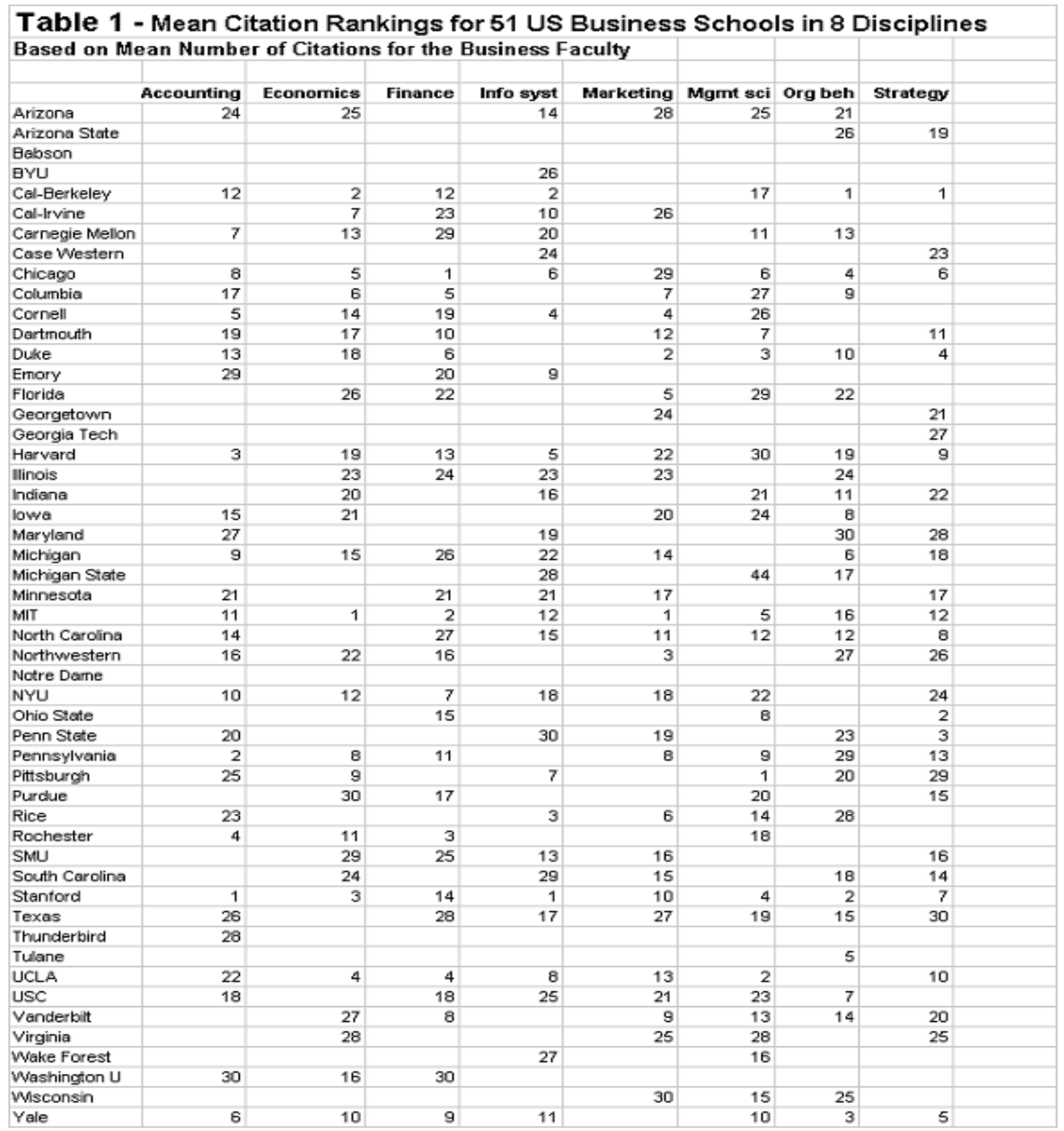


Tables 2 through 9 show rankings for faculties based on the mean number of citations per faculty member. The total number of citations is also shown, along with rankings on that measure, although ranking by total citations obviously favors schools with large faculties. Faculty size is given. There is a comparison with the ranking generated by US News and World Report in their 2003 update survey of the top schools in specialty areas of business for the six specialty areas that coincide with the eight under study. USNWR had surveyed deans and MBA directors at business schools to get "top 10" rankings for programs in those specialty areas.

The specialty programs keyed to the table number are Accounting (2), Economics (3), Finance (4), Information Systems (5), Marketing (6), Organizational Behavior (7), and Strategy (8). In each case, the top 25 schools in terms of mean citations are shown.

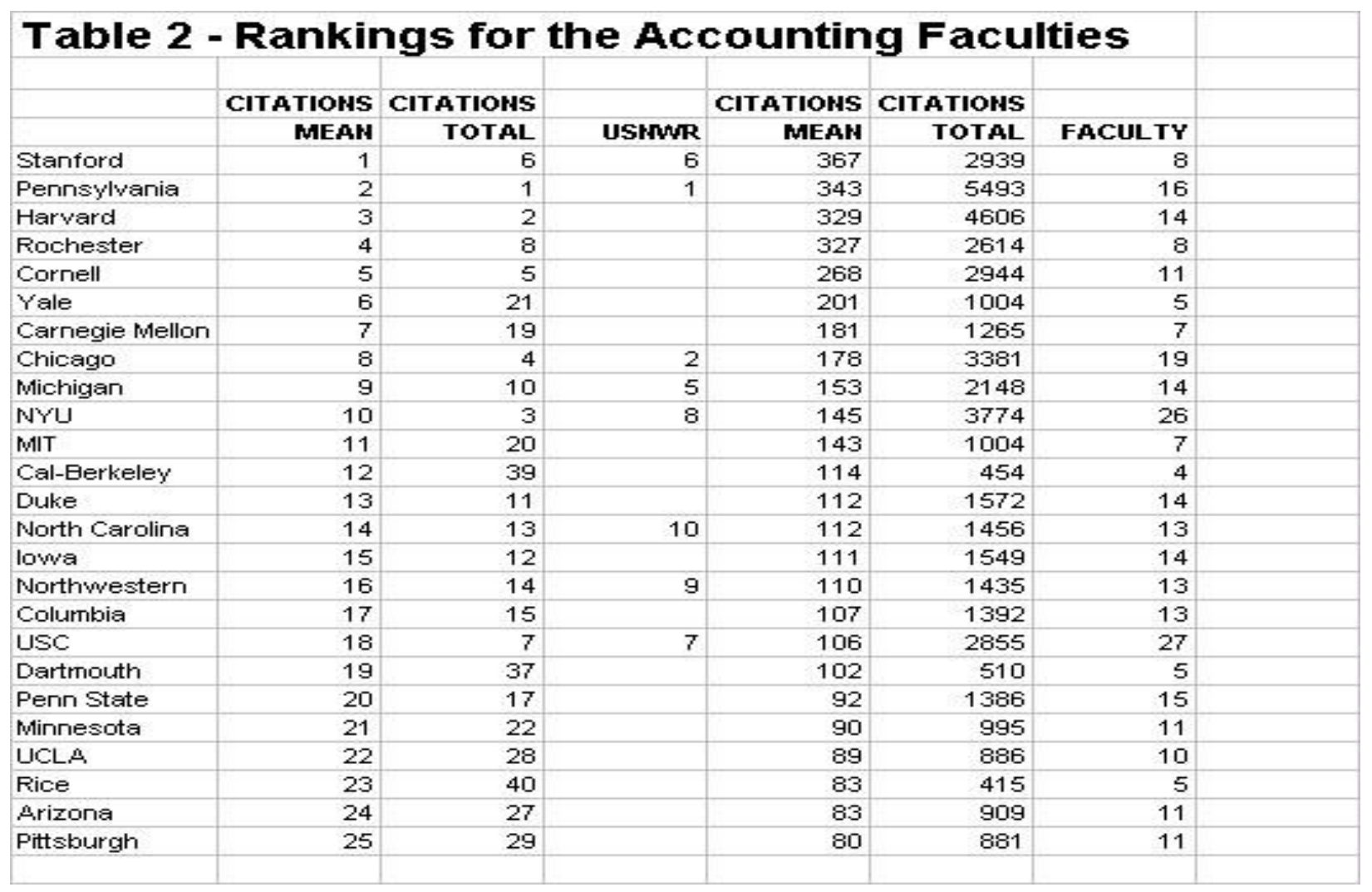




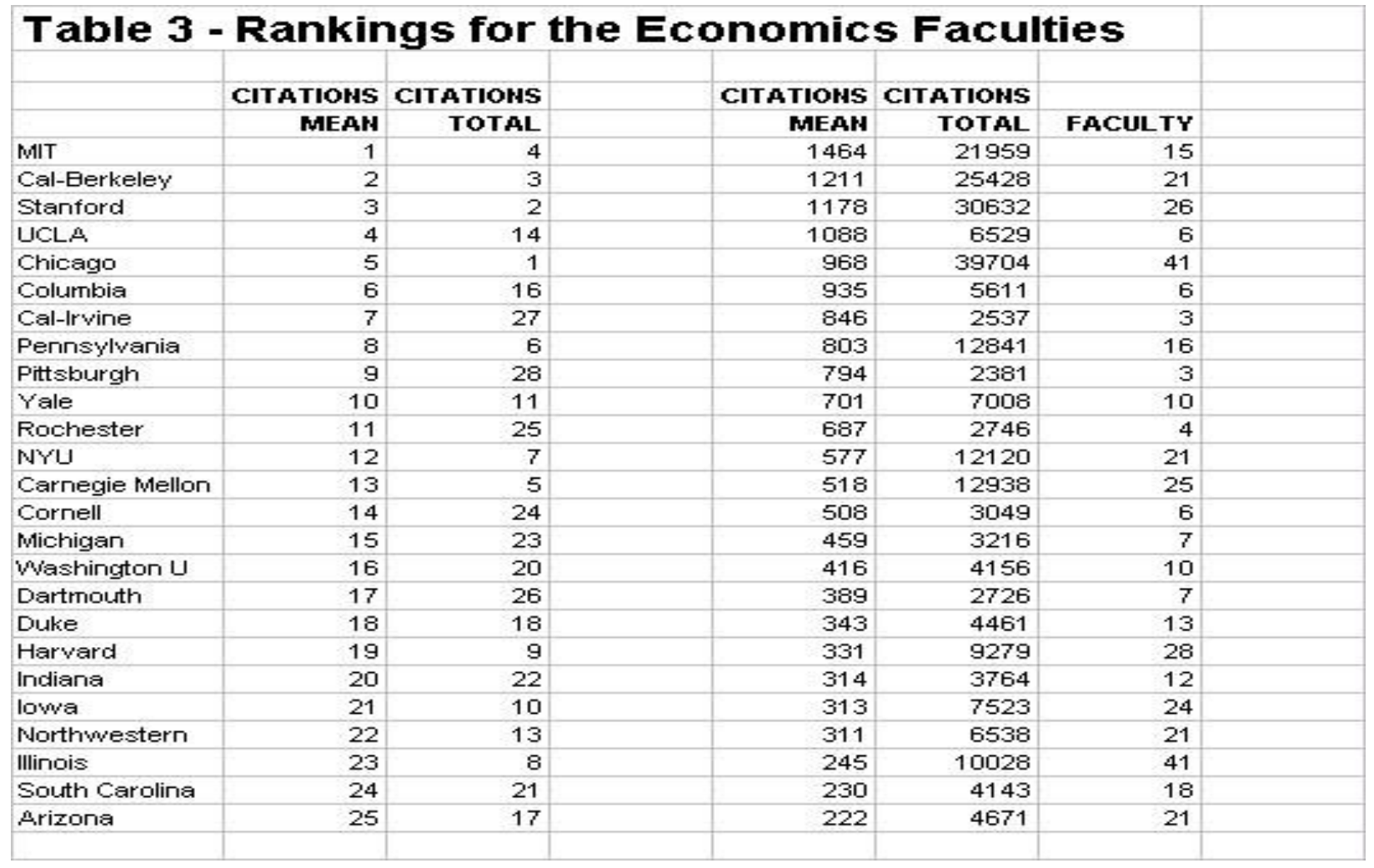

\section{Table 4 - Rankings for the Finance Faculties}

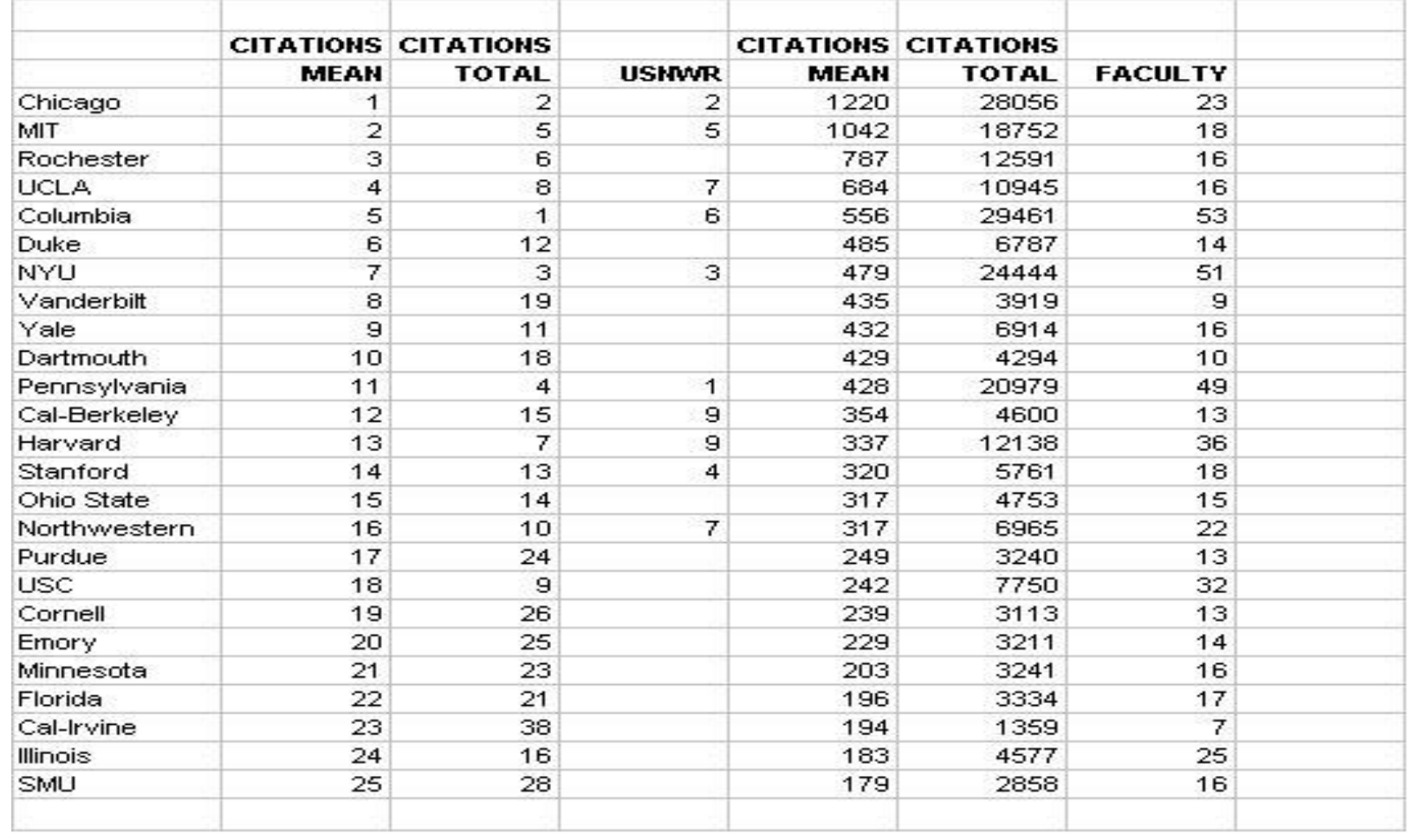




\begin{tabular}{|c|c|c|c|c|c|c|c|}
\hline & CITATIOHS & CITATIOHS & & CITATIOHS & CITATIOHS & & \\
\hline & MEAH & TOTAL & USFNMVR & MEAH & TOTAL & FACULTY & \\
\hline Stanford & 1 & 1 & 7 & 5110 & 15331 & 3 & \\
\hline Cal-Berkeley & 2 & 2 & & 1379 & 6893 & 5 & \\
\hline Rice & 3 & 13 & & 868 & 1735 & 2 & \\
\hline Cornell & 4 & 9 & & 719 & 2156 & 3 & \\
\hline Harvard & 5 & 3 & & 543 & 3798 & 7 & \\
\hline Chicago & 6 & 28 & & 486 & 486 & 1 & \\
\hline Pittsburgh & 7 & 8 & & 424 & 2545 & 6 & \\
\hline UCLA. & 8 & 20 & & 327 & 1308 & 4 & \\
\hline Emory & 9 & 15 & & 320 & 1598 & 5 & \\
\hline Cal-Irvine & 10 & 16 & & 303 & 1515 & 5 & \\
\hline Yale & 11 & 22 & & 297 & 891 & 3 & \\
\hline MIT & 12 & 12 & 1 & 293 & 1758 & 6 & \\
\hline SHu & 13 & 14 & & 230 & 1613 & 7 & \\
\hline Arizona & 14 & 7 & 4 & 203 & 2641 & 13 & \\
\hline North Carolina & 15 & 24 & & 195 & 586 & 3 & \\
\hline Indiana & 16 & 35 & & 192 & 192 & 1 & \\
\hline Texas & 17 & 5 & 3 & 188 & 3001 & 16 & \\
\hline NYU & 18 & 4 & 9 & 181 & 3258 & 18 & \\
\hline Maryland & 19 & 6 & 8 & 170 & 2724 & 16 & \\
\hline Carnegie Mellon & 20 & 11 & 2 & 170 & 2038 & 12 & \\
\hline Minnesota & 21 & 10 & 5 & 162 & 2101 & 13 & \\
\hline Michigan & 22 & 17 & & 149 & 1488 & 10 & \\
\hline Illinois & 23 & 23 & & 147 & 736 & 5 & \\
\hline Case Western & 24 & 18 & & 146 & 1463 & 10 & \\
\hline USC & 25 & 21 & & 145 & 1307 & 9 & \\
\hline & & & & & & & \\
\hline
\end{tabular}

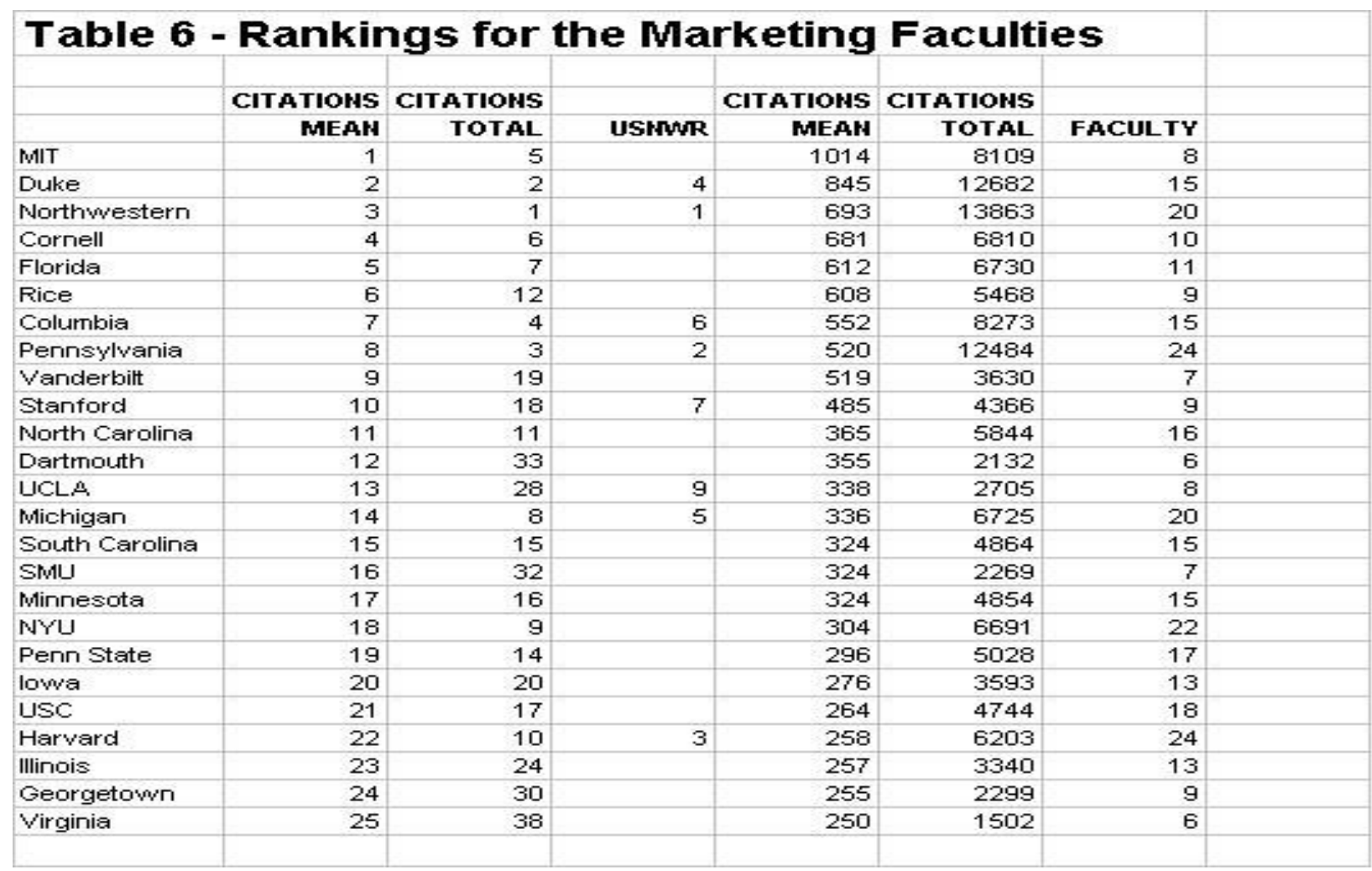




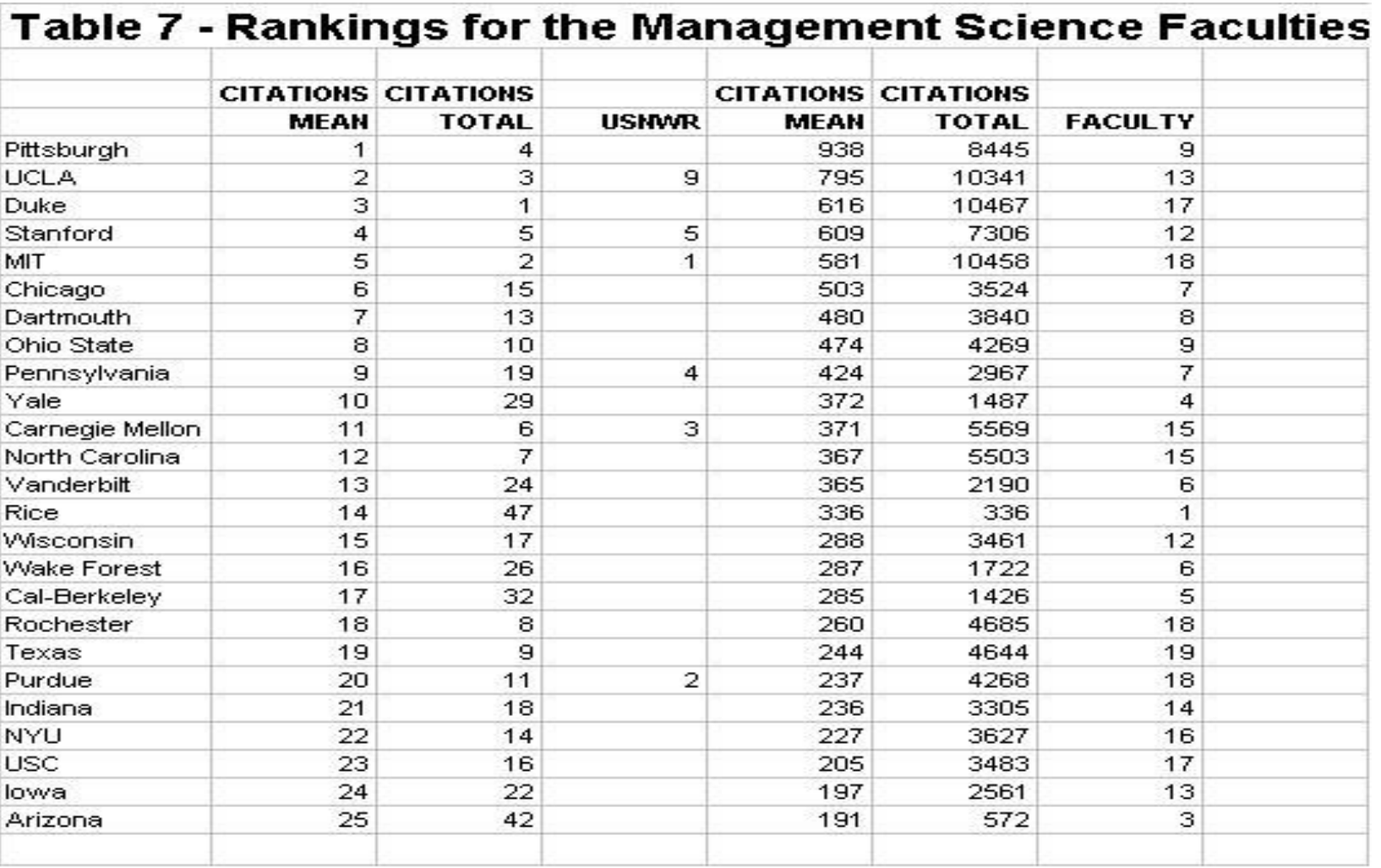

\section{Table 8 - Rankings for Organizational Behavior Faculties}

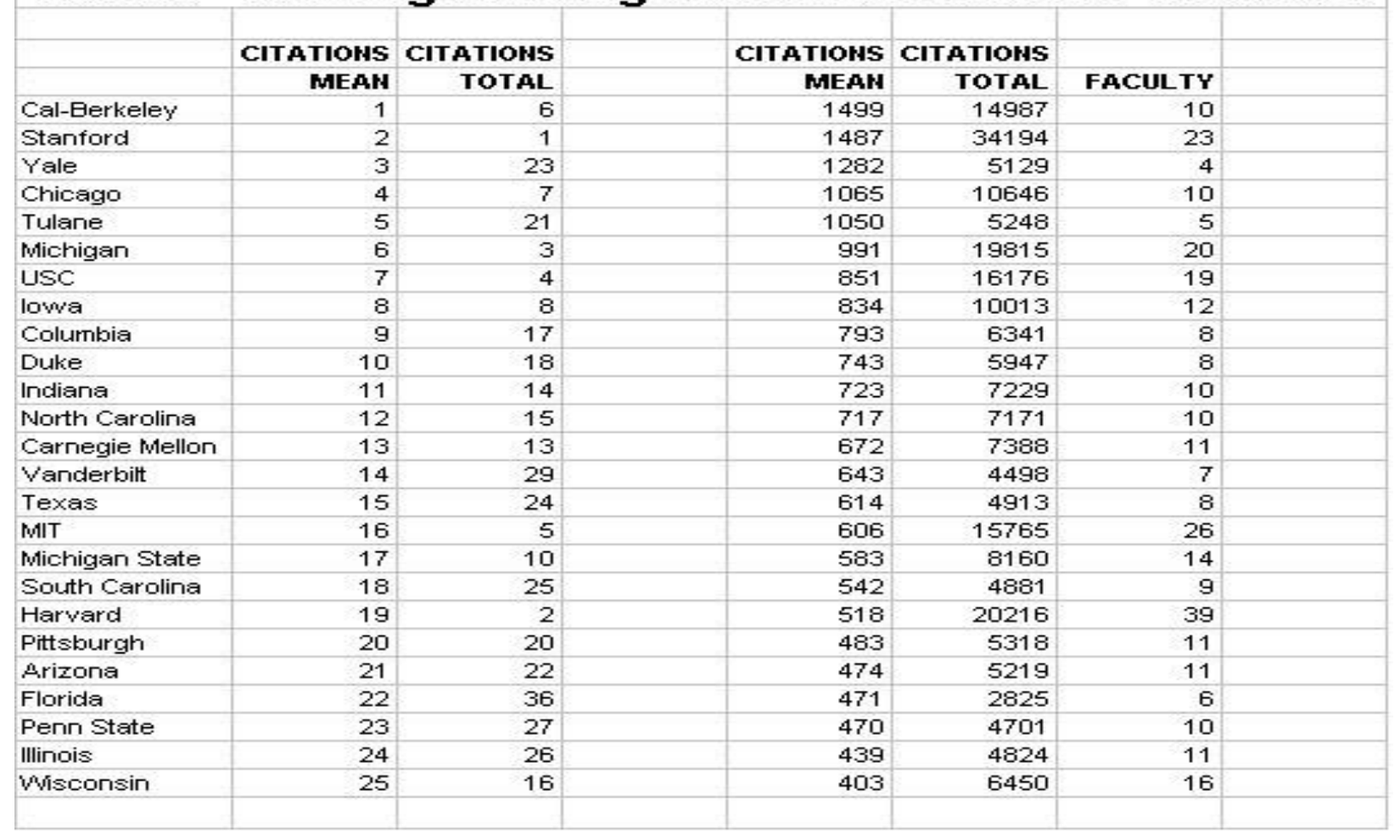




\begin{tabular}{|c|c|c|c|c|c|c|c|}
\hline & CITATIOHS & CITATIOHS & & CITATIOHS & CITATIOHS & & \\
\hline & HEAH & TOTAL & USRNHIR & HAEAH & TOTAL & FACULTY & \\
\hline Cal-Eerkeley & 1 & 2 & 10 & 1757 & 12297 & 7 & \\
\hline Onio State & 2 & 11 & & 1026 & 5128 & 5 & \\
\hline Penn State & 3 & 10 & & 867 & 5201 & 6 & \\
\hline Duke & 4 & 7 & 8 & 613 & 6740 & 11 & \\
\hline Yale & 5 & 29 & & 578 & 1734 & 3 & \\
\hline Chicago & 6 & 12 & & 528 & 4754 & 9 & \\
\hline Stanford & 7 & 4 & 2 & 516 & 7229 & 14 & \\
\hline North Carolina & 8 & 14 & & 500 & 3999 & 8 & \\
\hline Harvard & 9 & 1 & 1 & 497 & 23832 & 48 & \\
\hline UCL.A & 10 & 19 & & 473 & 2840 & 6 & \\
\hline Dartmouth & 11 & 16 & 6 & 446 & 3564 & 8 & \\
\hline MIT & 12 & 8 & & 443 & 5313 & 12 & \\
\hline Pennsylvania & 13 & 18 & 5 & 424 & 2967 & 7 & \\
\hline South Carolina & 14 & 35 & & 386 & 1157 & 3 & \\
\hline Purdue & 15 & 17 & & 375 & 2996 & 8 & \\
\hline SMIU & 16 & 28 & & 365 & 1825 & 5 & \\
\hline Minnesota & 17 & 5 & & 364 & 6913 & 19 & \\
\hline Muchigan & 18 & 6 & 4 & 356 & 6771 & 19 & \\
\hline Arizona State & 19 & 9 & & 350 & 5244 & 15 & \\
\hline$\checkmark a n d e r b i l t$ & 20 & 43 & & 335 & 335 & 1 & \\
\hline Georgetown & 21 & 26 & & 280 & 1958 & 7 & \\
\hline Indiana & 22 & 13 & & 275 & 4123 & 15 & \\
\hline Case Viestern & 23 & 25 & & 272 & 2176 & 8 & \\
\hline NYU & 24 & 15 & & 260 & 3643 & 14 & \\
\hline Virginia & 25 & 21 & 7 & 259 & 2330 & 9 & \\
\hline
\end{tabular}

\section{Discussion}

At first glance, the overall results of this study are what would have been expected. Four very prestigious schools were ranked within the top 30 for all eight disciplines (i.e. Chicago, Harvard, MIT, and Stanford). What was unexpected was that nine additional schools were within the top 30 seven times, and another nine schools reached that level six times. This means that there are a total of 22 schools with very solid performance across disciplines.

A second way to reach the same conclusion is to examine the number of schools that reached within the top three of the disciplines covered. Stanford and California reached these levels four times, MIT three times, and Duke twice. Eleven additional schools reached that level once (Chicago, Harvard, Northwestern, Ohio State, Pennsylvania, Penn State, Pittsburgh, Rice, Rochester, UCLA, and Yale). A total of 15 schools reaching into the top three says much for the depth of excellence across business schools.

Although there is a high degree of correspondence between the USNWR specialty rankings and the ones found through citation analysis, one may question why the correspondence is not greater. One possible reason is a difference in definition. For instance, this study included strategy and organization behavior, while USNWR had a category for management that included both strategy and organization behavior. Perhaps a more important difference is that of procedure. USNWR took essentially a reputational approach, surveying deans and MBA directors at business schools to get "top 10" rankings for these programs. The citation analysis provided results that were impartial, and not subject to individual opinion. It is not unreasonable that the results would be different.

There is a caution about using citation counts to compare faculty members from different disciplines with each other, because the disciplines differ in average numbers of citations. For example, the mean for all faculty members in this study was 311 citations, and the mean for five of the eight specialty areas was within 25 percent of that overall mean. The mean for economists, however, exceeded the overall mean by 49 percent and the organiza- 
tional behaviorists exceeded it by 72 percent. On the other hand, the accountants were cited at an average rate 69 percent below the overall mean. This means the average number of citations for the organizational behaviorists was five and one half times that of accountants.

The reasons for the differences across disciplines are probably due to factors unrelated to research productivity, such as nature of discipline-specific research and the reference practices used by journals. Such outside influences limit the value of cross-discipline comparisons. Average citation counts tend to be lower for schools whose faculty includes a high percentage of accountants and be higher for schools with a high percentage of faculty members in organizational behavior or economics.

It is noteworthy that 29 of the 51 schools (57\%) ranked in the top 10 for at least one discipline, and 17 out of $51(33 \%)$ ranked there for at least two. This suggests that there are a number of schools with high research productivity in multiple specialty areas. A search for a strong business program should not stop at the level of the school, but instead extend down to the level of the discipline.

\section{Implications}

Citation analysis can be used as a scoring system by business school faculty, administrators, students, prospective students, alumni, donors, legislators, and others searching for evidence of excellence in research productivity for various business schools. The technique has the advantages of being empirical, unobtrusive, logical, simple, robust, and relatively unbiased. The major drawback to use of citation analysis has been the difficulty in creating the data that could be applied to large samples of schools and specialties. The present study shows that such a database can be constructed, given current information systems technology.

The database of nearly 1.5 million citations was not created merely to serve as a simple scoring system to rank research productivity in business schools, however. Citation analysis can also be used to trace the origin of a stream of research, almost as if one were tracing back ancestry on a genealogical chart. Along the way, citation analysis is an efficient way to answer simple and not so simple questions. Is the stream more heavily weighted towards books, articles, or monographs? Is the apparent popularity of specific source materials supported by hard data concerning their use by others? Which journals have had the most impact?

Which specific articles in a field have had the most impact? Are there otherwise-unrecognized separate streams of research that are discovered when one travels upstream from the present broad confluence of the research river? How have the answers to any of these questions changed over time? Citation analysis can provide answers to these and other questions in an extraordinarily efficient way.

Although it can be an invaluable research tool, an immediate use for citation analysis may be as an assessment tool. In that role, it can be used to create both rankings and ratings for schools, departments within schools, business journals, individual faculty members, and prospective faculty members. Many of these data build upon each other, but each brick in the foundation is part of the citation analysis.

Schools can be assessed based on total citations, average citations, median citations, or combinations thereof. Comparisons can be made to any set of peer schools one may select. Although the research reported here used 1.5 million citations to assess 51 schools, the basic process can be applied to any set of schools or disciplines. In addition, any school or set of schools can be evaluated over a period of time to reflect trends in research productivity.

The assessment of research productivity at schools is based on the productivity of various constituent departments, and citation analysis can be used to make assessments at the department level with comparisons against peer departments or within the same department over time. Individual professors within a department can also be evaluated on the quality of research productivity, by using the same assessment tools and database. With controls to measure self-citations, the objective nature of citations analysis can be an important factor in evaluating research productivity component of promotion and tenure decisions. 
Two other important assessment problems concerning personnel decisions can be addressed through citation analysis. The first concerns the evaluation of the vitae of prospective new faculty members, at which time citation analysis can add a quality dimension to the assessment of publications included in a vita. The second concerns decisions about the quality of the journal in which a professor's article may appear. This is a difficult problem because individuals in one discipline may be called upon to assess the quality of an unfamiliar journal for the purpose of evaluating the work of a colleague outside of their discipline.

The merit of journals can be assessed using citation analysis. What is the total number of citations a journal is receiving? What percent of articles in a given journal are cited? What is the percentage of articles cited by authors in other journals? How soon after publication are articles being cited? Over what duration are journal articles being used? How often are self-citations appearing? The authors have begun a research stream to address these questions.

Schools, departments, journals, individual faculty members, and alumni are not the only elements that can be evaluated through the use of citation analysis. To paraphrase Vincent and Ross (2000), the opportunities for assessment using citations analysis are unlimited. It is hoped that this article provides some insight into the potential that the technique holds for providing an accurate assessment of a number of elements related to faculty productivity in US business schools.

\section{A Note On How The Data Issues Were Handled}

Who was included and excluded in the study? All fulltime professors with doctorates were counted, including visiting professors tenured elsewhere. If a visiting faculty member were tenured at another top 51 school, the faculty member was included in the study as being at the school that granted tenure. The study excluded emeritus faculty and adjuncts (even if they had doctorates) as well as faculty listed as "all but dissertation," fulltime lecturers, and research associates without doctorates. Deans were included if there was evidence the dean had a record of research activity in an academic business discipline.

What was done when data were unavailable on the website of the business school? Missing information was located by accessing the Digital Dissertations lists of doctoral dissertations accepted, Hasselback's Guide $(s)$ to Marketing and Accounting Professors, and internet search engines.

How were citation counts done? Citation counts were developed for all published work of each professor included in the study. The citation count process began with a review of the information available about the professor at the business school website. All business schools in the study included information about each member of the faculty. Many of the websites included both a biographical sketch and curriculum vitae for each professor.

The authors reviewed the available vitae information and went to the Web of Knowledge to get citation counts for the professor in two separate searches. The first search was of citations for the full last name, first and middle initial. Special care was taken to sort out the business school professor from any other cited authors with the same last name and first two initials. In several instances involving common names, the researchers had to make judgments based on the vita, the disciplines taught and researched, and the co-authors of the pieces.

The authors did a second citation count for each professor by using the last name and only the first initial. This additional search yielded about 30 per cent of the total citations in the study and was necessary because those who index the SSCI must index the footnotes in the form in which it is presented by the author(s) of the article they are indexing, and the footnote often has only has the last name and first initial. In this second search, numerous researchers in other fields were typically co-mingled with the business school researcher(s), so the judgment process described in the previous paragraph was necessary.

Which citations were included or excluded? Citations were included for both primary and secondary authors of journal articles indexed by the SSCI. For example, if Professor Wright was the first-listed author of an 
article and Professor Wong was a co-author of the article published in 1975 or later, then both authors receive full credit for all citations for the article.

Some journals were added to the SSCI in recent years. For years prior to being indexed by SSCI, primary authors were the only ones to receive credit for a citation of work that had multiple authors. For instance, Marketing Science began publication in 1982, but only articles published since 1987 attribute citations to secondary authors as well as primary authors. For some journals that either debuted or reached prominence after 1975, the start date for SSCI attribution of article citations to both primary and secondary authors may be after 1975. This limitation means citation counts for work done before SSCI began indexing the journal are only attributed to the primary author of multiple authored publications.

The citations count does include citations of one's own work. The authors found that there was no practical way to identify and omit self-citations on a mass basis, although that could be accomplished to respond to specific requests.

How were academic specialties selected for the faculty members included in this study? Academic specialties were developed by review of the 51 schools websites to determine the core specialties common to all schools: accounting, economics, finance, management information systems, management science, marketing, organization behavior, and strategy. Additional specialties included business law, business ethics, business history, risk and insurance, logistics, supply chain management, international business, international economics, public policy, real estate, entrepreneurship, negotiations, and electronic commerce. The additional specialties did not include enough faculty members at enough schools to permit meaningful analysis at the specialty level. All faculty members were included in any rankings of the 51 schools or doctoral programs.

\section{References}

1. Alexander, John C., and Mabry, Rodney H. 1994. "Relative significance of journals, authors, and articles cited in financial research", Journal of Finance, Vol. 49, No. 2 (June): 697-712.

2. Bayer, A. E., and Folger, J. 1966. "Some correlates of a citation measure of productivity in science", Sociology of Education, Vol. 39: 381-90.

3. Borokhovich, R.J., Bricker, R.J., Brunarski, K.R., and Simkins, B.J. 1995. "Finance research productivity and influence", Journal of Finance, Vol. 50, No. 5: 1691-1717.

4. Brown, L. D., and Gardner, J. C. 1985. "Using citation analysis to assess the impact of journals and articles on contemporary accounting research (CAR)", Journal of Accounting Research, Vol. 23: 84-109.

5. Garfield, Eugene. 1979. Citation Indexing: Its Theory and Application in Science, Technology, and Humanities. ISI Press, Philadelphia: 240-252.

6. Gupta, Uma G. 1997. "Using citation analysis to explore the intellectual base, knowledge dissemination, and research impact of Interfaces (1970-92)", Interfaces, Vol. 27, No. 2: 85-101.

7. $\quad$ Hamilton, D. P. 1991. "Trivia pursuit", Washington Monthly, Vol. 23: 36-42.

8. Hasselback, James R. 2002. Marketing Faculty Directory 2002-2003, Englewood Cliffs, N.J. PrenticeHall.

9. MacRoberts, M.H., and MacRoberts, B.R. 1989. "Problems of citation analysis: a critical review", Journal of the American Society of Information Science, Vol. 40, No. 5: 342-9.

10. Mahoney, Michael J. 1987. "Scientific publication and knowledge politics", Journal of Social Behavior and Personality, Vol. 2, No. 2: 165-176.

11. Peritz, B.C. 1992. "On the objectives of citation analysis: problems of theory and method", Journal of the American Society for Information Science, Vol. 43, No. 6: 448-51.

12. Robinson, Larry M., and Adler, Roy D. 1981. "Measuring the Impact of Scholars and Institutions on the Marketing Discipline: An Analysis of Citation Frequency", Journal of the Academy of Marketing Science, Vol. 9, No. 2 (Spring): 147-62.

13. US News and World Report. 2003. "America's Best Graduate Schools": 18-25.

14. Vincent, Annette, and Ross, Dianne. 2000. "On impact of faculty research - impact of citation analysis", Journal of Applied Business Research”, Vol. 16, No. 2: 1-14. 